\title{
ICTS: A catalyst for enriching the learning process and library services in India
}

\author{
Smita Chandra ${ }^{a, *}$, Vivek Patkar ${ }^{\mathrm{b}}$
}

\author{
andian Institute of Geomagnetism, Kalamboli Highway, New Panvel, Navi Mumbai 410 218, India \\ ${ }^{\mathrm{b}}$ D-1, Anita CHS., \# 612, Sector 6, Charkop, Kandivali (W), Mumbai 400 067, India
}

\begin{abstract}
Summary The advances in ICTs have decisively changed the library and learning environment. On the one hand, ICTs have enhanced the variety and accessibility to library collections and services to break the barriers of location and time. On the other, the e-Learning has emerged as an additional medium for imparting education in many disciplines to overcome the constraint of physical capacity associated with the traditional classroom methods. For a vast developing country like India, this provides an immense opportunity to provide even higher education to remote places besides extending the library services through networking. Thanks to the recent initiatives by the public and private institutions in this direction, a few web-based instruction courses are now running in the country. This paper reviews different aspects of e-Learning and emerging learning landscapes. It further presents the library scene and new opportunities for its participation in the e-Learning process. How these ICTs driven advances can contribute to the comprehensive learning process in India is highlighted.
\end{abstract}

(c) 2006 Elsevier Ltd. All rights reserved.

\section{Introduction}

The information and communications technologies (ICTs) have pervaded lives of even common citizens of a developing country like India. Realizing the power of these advances, a plethora of policies and projects on ICTs for development (ICT4D) have been initiated by the governments in developing countries to reap the benefit. The objective is to enable

\footnotetext{
*Corresponding author.

E-mail addresses: smitac_in@yahoo.com, smtcd@rediffmail.com (S. Chandra), vnpatkar2004@yahoo.co.in (V. Patkar).
}

the citizens to learn and participate in the development activities using the new technological means. The highly computer-mediated processes of production, storage and dissemination of information have made a far-reaching impact on the libraries and library professionals too. The ICTs in general are expected to make available more ubiquitous and extensive knowledge environments that would enable individuals to have access to quality information and facilities for discovery and learning. Continuous learning or education that would be the prime requirement in the future society is also well served by the ICTs. Web-based education that overcomes some of the capacity 
limitations inherent in the traditional classroom method of teaching and learning is now introduced in India and would help spreading education to people located even in remote places. The web and Internet, the core of the ICTs, are playing a crucial role in supplementing the library services and imparting education through e-Learning.

Internet access to information has now entered its second "phase" or "edition" as is evident from the somewhat audacious use of the term Web 2.0. In contrast to Web 1.0 where information and data were merely sought after, in the Web 2.0 environment people are looking to a new set of tools to aggregate, mix, modify, own and exchange microcontent in innovative ways (Alexander, 2006). "Openness" both in the terms of technologies used and the ideologies employed is yet another important characteristic of the Web 2.0. The "n-gen" or "digital natives" as the Web 2.0 communities are called, share contents because of their pervasive belief that sharing content or information is not unethical, though piling them up so as to make them redundant over time is antisocial (Downes). These "n-gens" have learned through networking that they can get far better support and information from one another, thus making redundant the role of any intermediary. The "use-centric" approach of "blogs", "wikis", "RSS feeds" and folksonomic metadata (metadata generated by users by attaching or tagging self-descriptive words to contents), are providing new avenues of social networking.

How such technological developments will impact the learning process is first analyzed here. It is followed by discussion about the changing library scene and emerging opportunities for its contribution to e-Learning in general. An overview of the Indian e-learning and library development scenario is presented next, and actions for strengthening the process are discussed to round off the paper.

\section{e-Learning}

The concept of distance education evolved primarily to overcome the problem of limited brick and mortar infrastructure and a need for the simultaneous physical presence of teacher and learner that characterize the classical classroom-based learning model. The development of ICTs provided a great fillip to this learning mode especially because of increased avenue for interaction between teacher and learner and among the learners through e-mail and web postings. Due to these advantages, the e-Learning, a term initially applied to distance learning via electronic media, is now well established. It is now extended to incorporate traditional research, learning and teaching in the digital world, and a blend of face-to-face and online instruction and course materials. From its earlier version of computer-based training (CBT), where materials were stored on CD-ROMs, the digital form was converted to web-based training (WBT), which could be accessed via a browser from any desktop with internet connectivity. Various stages in the e-Learning process are (Ghosh, 23):

1. Pre-authoring: Content owners and developers assess the contents as per the learning objectives of a course. Much of this content is offline and needs to be converted to WBT material. This includes assessing needs and defining roles and skill requirements.

2. Content development: It includes designing and developing courses and contents. The organization might be required to integrate existing programs with new courses and identify methodologies to adapt, such as blended or pure webbased or traditional courses.

3. Course management: Done by people trained in learning management systems (LMS), who understand the functionality of the system and can act as administrators.

4. External database interface: This involves the role of the learning organization to capture and access knowledge. Knowledge management requires capturing "tacit" knowledge and learning into the system so as to keep the knowledge repository, or base, updated.

5. Delivery: Ways by which e-Learning can be delivered through standard software like browsers, collaborative tools like chat and online discussion boards.

According to Downes, in the evolving Web 2.0 environment, the e-Learning is expected to shape as "a shared domain of interest" where "members interact and learn together" and "develop a shared repertoire of resources" (Downes). Therefore, as the web turns into a content-authoring tool, online learning ceases to be a medium alone and becomes a platform where students and teachers create the learning contents. Such a web-node becomes a personal learning center where content is reused and remixed according to the student's own needs or interests. In other words, it becomes a collection of interoperable open-source applications, used by educational institutions at large, resulting in a contradictory mix of technological and ideological openness on the one hand and university governance restrictions the other. An example of such an e-Learning initiative is the Information Management Resource Kit (IMARK) [http://www.imarkgroup.org/ 
index_en.asp] in the subject area of agricultural information management. This kit, developed in five languages by the UNESCO, FAO and partner organizations, aims at mobilizing and building upon the existing scattered material to create a comprehensive suite of distance learning resources for information management and exchange amongst farmers, agricultural scientists and technologists, students, meteorologists, geologists and any allied subject of importance to the agricultural domain worldwide.

In the US, $70 \%$ of all institutions offer distance learning and $80 \%$ offer hybrid courses where instructors post material on web for students for further discussion (OCLC, 2003). In Canada, e-Learning environments have an estimated growth rate of 20-30\% per year (CARL e-Learning Working Group, 2005). Countries like the UK and Hungary have a national policy to encourage people to be familiar with new technologies that impart education. Lifelong learning through distance education programs and e-Learning is therefore fast catching up (Information for All Programme (IFAP), 2005). Though access to suitable information technology is a prerequisite for e-Learning, the skills needed to close the digital divide honed in by e-Learning makes it a viable communication media for the developing world (Detecon and Diebold, 2006). By addressing the cultural issues, e-Learning can minimize the gender bias in many developing nations that have high rates of female school drop outs. The illustrative and persuasive capabilities of the modern multimedia can address a number of environmental issues by combining an interactive exploration of topics and rich visualizations. For example, models and graphics on diseases like HIV and AIDS and tuberculosis; those on farming using the latest scientific equipments and techniques; or those on natural or terrorist disaster preparedness and mitigation can help in increasing an individual's awareness and changing the mindset and behavior. It is envisaged that e-Learning will move beyond the classroom-oriented teaching or learning to life-long training and workplace learning (Rosenberg). For realizing such a scenario a host of technological solutions and novel approaches by the institutions imparting both formal and informal training would be necessary. The irreplaceable role of libraries, particularly the public libraries, as knowledge and cultural institutions cannot be ignored.

\section{Learning landscapes}

\section{e-Portfolio}

An electronic portfolio or e-Portfolio is one way to enhance quality in an education system. A "web- folio" as it is often referred to, is a web-published collection of documents, information, audio and video clips that showcases the abilities of comprehension and organization of knowledge gained by an individual with respect to any topic or course (Good, 2006). With no restrictions on the amount of information to be added, deleted, or shared, it gives students a personal space to pose questions, put up drafts, link to and comment on relevant sources, and to link with other learners with similar interests and create an ad-hoc learning community.

In Fig. 1 Tosh and Werdmuller, have modeled a comprehensive learning landscape that illustrates the evolution of a learner's e-Portfolio through different types of interactions. Such an e-Portfolio, according to them, is a place where a student can construct a digital identity which connects resources, experiences and tutors. It creates communities of knowledge transfer and development, allowing users to become contributors as well as recipients. Therefore, a personal digital diary would have a learner-centric portfolio for assessment, accreditation, presentation, employment, reflection or deep learning, and personal development. Open access to such material for assessment, sharing, reviewing, and commenting anytime would enrich the learning of all those involved and interested in the topic. Incorporating elements of e-portfolios, webloging and social networking thus creates extended learning landscapes.

\section{Learning objects repositories (LOR)}

Institutions with functional Open Access Institutional Repositories (IR) have a role in further enhancing e-Learning environments (Dempsey, 2006). Apart from supporting open access and preserving the intellectual assets of an institution, such IRs facilitate the members' efforts to develop their own work further, that is, to organize their resources, link their writing to others and work with co-authors, goals akin to e-Portfolios. When such webfolios are integrated with IRs, they can act as LOR, supporting the use and exploitation of interoperable collections and objects of geographic, cultural, scholarly or scientific nature from libraries, archives and museums. In turn, they facilitate exposure, discovery, and retrieval of these resources, which can be harvested by e-Portfolios, thus completing the circle.

As depicted in Fig. 2, such LORs could act as preservation and collection building tools (ELAG, 2005). The role of the librarian could be metadata editing, evaluation, and providing access to materials held therein, administering IPR and other licenses. 


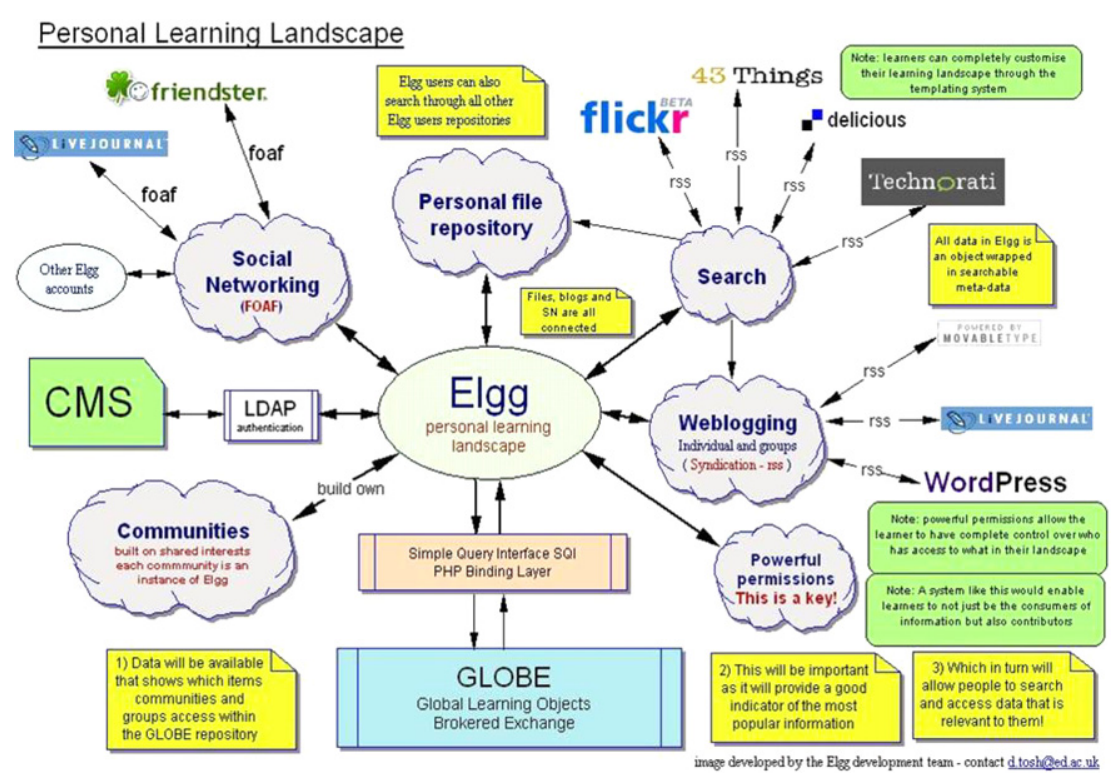

Figure 1 A learning landscape (Source: Tosh and Werdmuller).

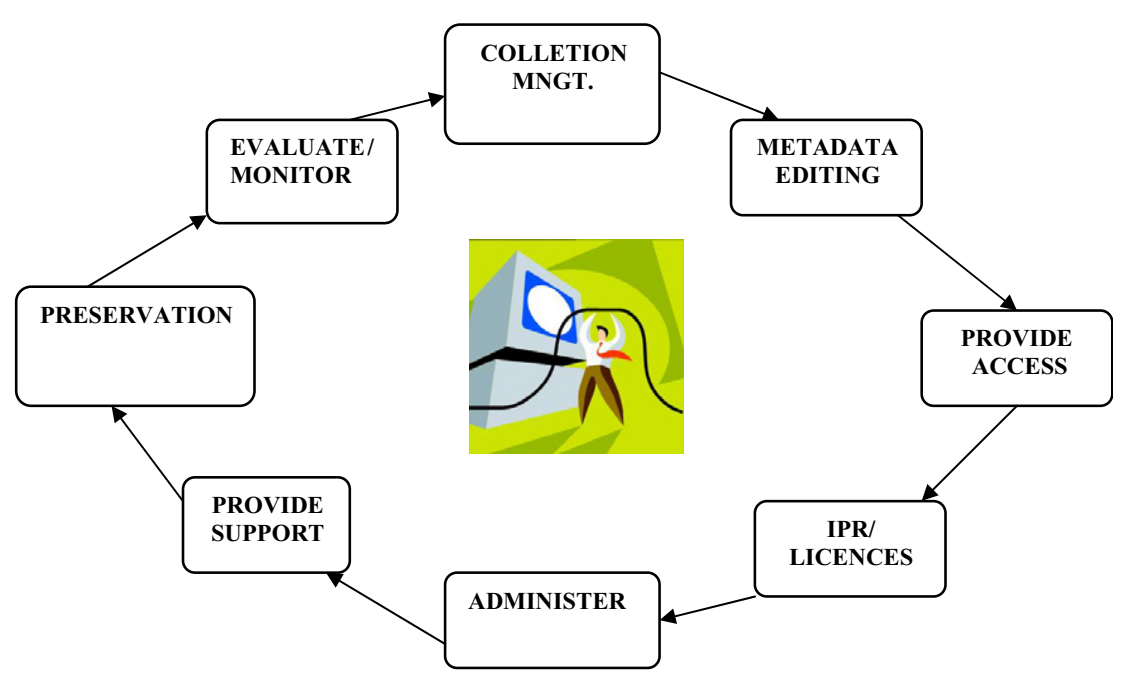

Figure 2 Learning object repository system and services (Source: ELAG, 2005).

\section{Cyberinfrastrucutre}

The "cyberinfrastructure" as reported in the Atkins et al report (2003) aims at empowering radical new ways of conducting research through the applications of information technology. Physical infrastructure embedded and hidden in the use of high-speed networks and advanced computing forms one layer. Intangibles like software, design processes, raw data and processed information constitute another layer. The cyberinfrastructure layer, in the broadest sense, constitutes the inbetween layer of enabling hardware, algorithms, software, communications, institutions and personnel. By integrating both these layers, the cyberin- frastructure layer develops and deploys applications that contribute to enhancing the total quality of information processing. Such a layer can act as an enabler by hosting the technologies that serve the entire learning landscape comprising of digital libraries (DLs) and e-portfolios. Such grid technologies have the capability of facilitating more secure, efficient and better e-Learning solutions. The cyberinfrastructure would promote extensive networking and multidisciplinary research leading ultimately to the formation of e-science/e-research communities (Patkar \& Chandra, 2006). The grid technologies are facilitating a second phase of DL, by not only providing more secure solutions for implementations but also more secure 
environments for better DL services. Similarly, these grids could act as hosts to the LORs, storing complex digital objects, thus rendering enhanced role for the librarians towards the long-term preservation and curation of data (Messerchmitte, 2003).

\section{E-Learning and libraries}

E-Learning, in the wider perspective, connotes a knowledge-centric rather than a course-centric approach. Such an approach allows the user to query the knowledge base to learn about any topic. This knowledge base builds on a variety of resources such as documents, websites, experts, communities, tools and events. Libraries as hosts to many of the elements of this knowledge base act as an enabler to the e-Learning process. Providing access to information sources and repositories such as archives, print and electronic collections and databases could educate users further. It would be interesting to understand the role of the library in such a learning milieu.

\section{Current library services}

Library resources and services act as primary knowledge resource for both research and training, and therefore, libraries as institutional access points play an important role in the learning process. Research productivity has generally been found directly related to access to the library resource. Libraries have traditionally been focusing on infrastructure development to create systemwide efficiencies by providing integrated library catalogs and openly available metadata-based online support and access to journals and other information sources for resource sharing. These efforts are directed at enhancing the effectiveness of technologies in the library operations; however, the issue today is how technology will influence the way library users behave and expect (Dempsey, 2006, p. 30) The current "pull" type library services have aimed at bringing together services and data holdings from different sources to meet the user demand. Integrated library systems, openly available abstracting and indexing services and electronic journals supporting the library websites have traditionally been operated as standalone systems. Such library systems shared resources across networks but limited user interactions for co-creation, and modification, tailored to individual needs.
The omnipresent web has given the user a creative expression and a feeling of fulfillment, of having searched all the information ever produced for their information needs. In order to serve the clients in such an environment the library is increasingly required to adopt the "push" type approach for library services. For example, libraries today are gathering data regarding users (like checked-out items, preferred searches and search alerts), RSS aggregators, bookmarks, toolbars, plug-ins and various mechanisms and employing them to configure, shape and integrate the library resources and extend services to the networks and even personal digital diaries of the interested users. In other words the library is to compete with other information sources and service providers.

\section{Future library services in e-Learning environments}

The cultural renaissance brought about by Web 2.0, a term first coined by Tim O'Reilly and Dale Dougherty, is being extended to techniques of librarianship. The term "Library 2.0" is being coined and deliberated upon (Mannes, 2006). The world today is driven by access, information, and speed. Integration of the Library 2.0 environment with the IT enablement of the learning process promises eliminating barriers of time and distance, creating on-demand services and providing universal learning opportunities for people-an extensive assortment of information and education at the click of a mouse. Such a scenario raises the question as to how libraries can blend or redefine their own services and systems so as to address the needs of the new e-Learning environments.

The e-Learning environments provide libraries the collaborative possibilities of exposing library services, creating and maintaining digital asset repositories and creating standards for interoperability. Libraries have the challenge of deploying their services in new learning environments, using a technology that is constantly evolving. Librarians have a vital role to play in each of the stages of the e-Learning process. Working in synchronization with the faculty members, IT specialists and instructional designers, library professionals, in particular, can gainfully contribute to the preauthoring process, as also with metadata schemas for content development and management (CARL e-Learning Working Group, 2005, p. 22).

Further, creation and sharing of peer-reviewed learning resources with colleagues in specific disciplines can lead to continuous improvement of 
the learning resource. This can reap economic benefits by avoiding duplication of common learning material. Thus, digital rights management (DRM) that harps on the critical mechanism of intellectual property can be efficiently performed as libraries with their long-standing experience in dealing with copyright issues can provide significant input.

As shown in Table 1, collaborative opportunities also exist towards integrating existing and new library services into the e-Learning infrastructure by offering new form of delivery like displaying a variety of information windows in the digital diaries of users in customized formats. Introducing copyright information and software that checks plagiarism, providing virtual reference services (VRS) and thirdparty commercial information services, and embedding training modules to assist in information seeking, are some other library services in e-Learning environments. Library services should be integrated with LMS such as WebCt, Blackboard, DesireLearn, ANGEL or Moodle at the point of need to be most effective. It should be incorporated in such a manner that a single login makes possible access to all course components, direct links to e-journal articles, interlibrary loan, online interactive reference services and content resources to the LMS (CARL e-Learning Working Group, 2005, 22). Librarians could work in conjunction with faculty to:

- offer classes or embed courses to sharpen the information-seeking skills of students,

- help them to explore, besides finding, the most useful information resource,

- guide in the consolidation of sharable resource libraries,

- assess and evaluate a resource critically, and

- organize metadata for online resources

\section{Indian e-Learning scenario}

As the second largest populous nation in the world, India has the dubious distinction of having the world's largest illiterate population. A recent amendment to the Indian constitution makes education a fundamental right for children in the age group of six to fourteen. However to meet the educational demand of over 300 million students in this age group, provision of adequate educational infrastructure like classrooms and laboratories in schools and colleges has hardly been possible. The literacy rate in the rural areas is just 56\% (Singh, 2002). India has 192 million illiterate women, which is nearly one-third of illiterate women in the world. There is also an acute shortage of good teachers. The average teacher to student ratio is 1:58 in rural areas. No wonder inexperienced and not so competent teachers are being employed many times resulting in poor quality of teaching. Despite all such limitations, the country has a large turn around of a far more enthusiastic younger generation that strives to acquire skills, particularly in the IT domain and reading and writing in English language. Still there remains a huge challenge of providing basic education to all. Moreover, in the emerging economic scenario, learning will have to be a continuous activity, as against a "one-time" activity in the past. There would be nothing as the "right" skills forever.

To meet the requirement of basic education on the one hand and that of upgrading and renewal of skills of such a large workforce on the other, eLearning is seen as one of the best options for India as:

- a few good teachers can reach a whole lot of population, without restrictions of geography, time, sex, religion, caste or creed,

- better quality of study material and collaborative tools like discussion boards, chats and email support give students more interactivity,

- the self-paced nature of the e-Learning modules allows even the slow learners to catch up with the rest of the class,

- e-Learning emphasizes continuous learning and promotes "just-in-time" and "just enough" learning for busy professionals or executives,

Table 1 e-Learning and library.

\begin{tabular}{ll}
\hline Stage of e-Learning process & Library involvement \\
\hline Pre-authoring & Selecting/evaluating/assessing learning objects \\
Content development & $\begin{array}{l}\text { Metadata/information seeking training modules/federation of integrated } \\
\text { library systems }\end{array}$ \\
Course management & Plagiarism, intellectual property rights/copyright/digital rights management \\
External database interface & Knowledge management activities and virtual reference service \\
Delivery & Delivery
\end{tabular}


- the scalability and ubiquity enables employees to be trained on a variety of skills and technologies conveniently and cost effectively.

The rhetoric apart, the reality is that e-Learning is still a new phenomenon to a vast majority of the Indian universities and institutions. It is currently more prevalent in the IT sector with most IT firms offering online training courses for their employees stationed at geographically dispersed locations.

Several universities in India do have a distance education program for undergraduates and postgraduates in disciplines of arts, commerce and mathematics using some form of communication media, however, their intake and growth has been far from the desired proportion (Ghosh). These courses by and large still supply traditional paperbased notes and reading material and supplement that by organizing once a week physical contact with local designated instructors for the registered students. Some of the major reasons for the nonuse of ICTs for this purpose are as follows:

- lack of penetration of ICTs in semi-urban and rural India,

- lack of reliable communications infrastructure and insufficient bandwidth,

- lack of course content, except in the field of IT,

- lack of content in vernacular Indian languages as most of the content is still in English,

- lack of psychological acceptance due to absence of the "personal touch" associated with classroom lessons,

- lack of teachers and experts for development, deployment and delivery of the e-Learning solutions, as also a lack of experience and understanding of the e-Learning market,

- lack of standards and a long gestation period for implementation.

A few educational institutions in India that offer e-Learning courses are (Patel, 2006):

1. Birla Institute of Technology and Science (BITS), Pilani,

2. Indian Institute(s) of Technology (IITs),

3. Narsee Monjee Institute of Management Studies (NMIMS), Mumbai,

4. Visvesvaraya Technological University (VTU), Bangalore, Karnataka,

5. Y.B.Chavan State Open University, Maharashtra,

6. Rajiv Gandhi Technical University, Madhya Pradesh,

7. Indira Gandhi National Open University (IGNOU),
8. All India Council for Technical Education (AICTE),

9. Indian Council for Agricultural Research (ICAR),

10. National Council of Educational Research and Training (NCERT),

11. University Grants Commission (UGC).

These institutions of higher learning have wherewithal to set up on-line video conference facilities and virtual laboratories to give the feel of a real laboratory. India is the first country to have an exclusive satellite namely, the EDUSAT for educational purposes that was launched in September 2004. EDUSAT networking is being implemented through the apex institutions (the last five in the above list) to expand the educational facilities to the remotest areas where a college-level educational institution is located. For example, the students and faculty of 120 engineering colleges affiliated to Visvesvaraya Technological University spread over urban and rural parts of the state of Karnataka are greatly benefited by the sessions on technical topics conducted daily through the EDUSAT as they get an opportunity to interact with the experts and also see the best visual representations of the concepts and working of instruments and machines that is otherwise not possible. About 2700 schools in the backward districts of the country are also using this facility with advantage. It is noteworthy that ten schools for blind are served by the special transmission organized via EDUSAT in the state of Gujarat (SPACE, 2005).

\section{LIS services and e-Learning developments in India}

The concept of e-Learning has not yet been fully conceived in the LIS field though there are a few exceptions of prototype development of e-Learning modules for library management. Libraries in India in general are not yet equipped with the necessary infrastructure, both hardware and software, to face the challenges of e-Learning in the broader term. So far only a handful initiatives and experiences with library networking and collaboration, DLs (including one on traditional knowledge and experiments), IRs and open access publishing are available in the Indian context.

The "Digital Library of India" project is one development under which digitizing books predominantly in the Indian language is undertaken as a contribution to the digitization of one million books project initiated by Carnegie Mellon University (Balakrishnan, 2005). This is done using the specially 
developed "Om" language transliteration package. Application of Next Generation technology and improved quality of scanning and transliteration software employed in such projects would help bring digital audio and video beyond text to the millions of illiterate and semi-literate rural masses. Similarly a strategic plan for a digital library for Indian farmers (DLIF) (Jain and Goria, 2006), if implemented, could open the gates for online publication and dissemination of multilingual text, audio and video documents for farmers. Besides providing authentic information and agricultural literacy programs to the 103 million farm families spread across 127 agro-climatic zones on the subjects of crops and animals, such a DL could be a source of authentic extension literature for the agricultural extension workers. Each DL course and or project could be so structured so as to have components of information literacy for these workers. Besides addressing the professional information needs of individuals, such information literacy modules could incorporate training on legal issues for example, issues related to land rights or those related to marriage and dowry, bank loan procedures, employment advice, education information by being linked to university systems, etc. Such a DL could play a pro-active role of a public library linking farmers at the local level to the national and then the international level.

IRs in the country, though few at present, offer the promise of opening the gates of knowledge for academics, researchers and students by supplying relevant information at affordable price. Some of the important open digital repository initiatives in India are:

1. Eprints of the Indian Institute of Science (http://eprints.iisc.ernet.in),

2. National Chemical Laboratory (http://dspace.ncl.res.in/dspace/index.jsp),

3. National Centre for Radio Astrophysics (http:// ncralib.ncra.tifr.res.in/dspace),

4. University of Hyderabad (http://202.41.85.207: $8080 /$ dspace/index.jsp),

5. Indian Statistical Institute, Bangalore (http:// library. isibang.ac.in:8080/dspace/),

6. Indian Institute of Technology (IIT), Delhi (http://eprint.iitd.ac.in/dspace).

In addition, open access publishing in India is coming up in a significant way. This can be seen from the availability of several open access journals brought out by the,

- Indian National Science Academy (http://drtc. isibang.ac.in/insa),

- OpenMED (http://openmed.nic.in).
Such open archiving IRs and DLs in the country could be harnessed to aggregate, create and disseminate a knowledge base that is merged with local content wherever possible. They could leverage e-Learning environments in the country using the increased bandwidth and improved services to build various customized training applications for rural India. The cyberinfrastructure efforts of the country namely, GARUDA, that is a collaboration of physical and natural science researchers and experimenters on a nationwide grid of computational nodes, mass storage and scientific instruments, can play an important role in technological enhancement to permit ubiquitous environments (Mohan \& Ramkrishnan, 2006). While the Indian government has stressed the role of books in the learning process, the role of libraries towards literacy has received lesser attention. The current framework for distance education programs in the country should incorporate access to library resources and services equivalent to the students in campus settings. Besides students could be offered VRS by libraries to assist them in searching online catalogs, finding journal articles, ways of effectively using the internet to find quality, reliable and authentic sources. Such services could also enlighten students on issues of plagiarism and copyrights. These type of environments could help the national literacy mission too by enabling a parallel learning process, thereby breaking upon the need for the cycle of literacy followed by computer and/or information literacy.

A modular approach to the curriculum for Information studies, proposed by Lang in 1982 in a UNESCO report, and later advocated by C.R.Karisiddappa (Karisiddappa, 2004), building upon Vasant Gowariker, proposes an LIS graduate coursework with six core modules and one elective module. The worked out modules as stated by them are:

Module-1: Foundations of Library and Information Science,

Module-2: Knowledge Organization, Information Processing and Retrieval,

Module-3: Information Sources, Products and Services,

Module-4: Management of Library and Information Centers/Institutions,

Module-5: Information Technology: Basics and Applications,

Module-6: Research Methods and Statistical Techniques,

Module-7: Electives: Information Systems.

Each of these modules can be developed into a web-based e-Learning component as is evident by 
some segments of the LEEP 〈http://www.lis.uiuc. edu/programs/leep $>$ program for the LIS course being offered by the University of Illinois UrbanaChampaign. This way of imparting learning would further enhance effectiveness.

Library and Information Science faculty in the country have already started exploration of the effective medium of the web to enhanced learning. VidyaOnline a prototype web-based hybrid, modular, interactive learning system for the library and information science courses was developed by Vidyasagar University, in the state of West Bengal (Mukhopadhyay, 2006). VidyaOnline supports all the forms of the Virtual Learning Environment (VLE) namely, WBT, online learning and a digitally interactive student management subsystem. The software architecture is comprised of Free and Open Source Software (FOSS): Linux as operating system, Apache as a web server, MySQL as a relational database, PHP as a scripting language (LAMP) architecture and the Moodle course management system. To begin with, a course on the MARC 21 Bibliographic Format and KOHA, the first open source web integrated 4th generation library management software was introduced. The future extensions envisage development of a Benagli language based courseware on $\mathrm{KOHA}$, in view of the immense possibilities that the software offers for automation of public libraries in West Bengal.

Similarly, the Department of Library and Information Science of IGNOU developed an e-Learning system for LIS courses under the National Information System for Science and Technology (NISSAT) project. The e-Learning module was aimed at providing skills to the learners in practical work of creating and searching databases for the Windows version (WINIS) of the CDS/ISIS software that is an information retrieval package developed by UNESCO (Kanjilal \& Ghosh). Keeping in mind the fact that a vast majority of learners may not have Internet accessibility, the e-Learning course for WINIS was developed in a dual mode, via Web and on CD-ROM. The LMS incorporates e-mails, chats, discussion forums, automatic assessment, student tracking and feedback generation with great emphasis being paid on helping the learner in a guided learning process.

Recently an interesting web-based e-Learning initiative in the LIS was launched namely, the IndoGerman "eGurukul" on DLs. This is a joint e-Learning initiative of the Document Research and Training Centre (DRTC), Bangalore using the Moodle software (http://drtc.isibang.ac.in/mmb). A host of courses are offered. Registered students receive attention by individual instructors, followed by an online assessment. However, the true capabilities of this initiative would be achieved by incorporating practical experience with its theoretical courses, for example, by creating a $D L$. Students stand to gain further if this initiative could be linked with international projects for course credits and certificates, thus also acting as a source of continuing education program for the working professionals.

\section{Concluding remarks}

The vast potential of ICTs application in development in general and in education in particular, if exploited suitably, can do wonders for a country like India. For instance, the virtual classes and DLs embedded with a local language interface can enhance access to knowledge for the rural Indian youth to compete reasonably well with others (Yajnik). Since e-Learning modules offer rich visualizations they could help even ordinary people to march on the information literacy path irrespective of their socio-economic status.

It is envisaged that e-Learning can be successfully used to re-skill large workforces that become redundant, for example in the wake of closure of outdated industrial units or their diversification (Detecon and Diebold, 2002). It can also help acquiring necessary details and develop entrepreneurial attitude among the unemployed young persons who can look beyond jobs at the Call Centers. Experience available from a pilot project on networking of six villages by ICTs to develop a database about relevant local information and its dissemination shows promising results (Chandra, 2002).

The workplace training of technical and other staff is becoming essential for firms to remain competitive. And they can suitably use e-Learning and allied methods for training purposes because that can be done with the least disruption of the normal activities.

Libraries will have the challenge to remain relevant in the Internet-driven information explosion era. They will be required to constantly adapt to the changes brought about by advances in ICTs (Patkar, 2006). Library professionals would also play a significant part in e-Learning process as discussed in the section "Future library services in e-Learning environments". For this purpose tailored programs for the professional staff are to be organized to update their knowledge periodically. Moving further, the libraries can contribute markedly to multi-disciplinary research by employing numerous features of the cyberinfrastructure (Patkar \& Chandra, 2006). 
There are more than 54,000 public libraries in India and sizable numbers of them are languishing. They deserve special attention because they can act as vital nodes in spreading literacy and providing local information. Time-bound programs are needed to modernize these public libraries at the earliest. Coverage of the public libraries through EDUSAT network could also prove beneficial. Efforts by the organization like DELNETDeveloping Library Network, New Delhi (www. delnet.nic.in) to establish "knowledge centers" by bringing together the public libraries and learning institutions in each region of India is one noteworthy initiative (Kaul, 2006). However, it is a stupendous task and would require substantial contribution by private organizations too.

It happens that like any other new medium, e-Learning, while solving the problems of the previous media, creates new ones of its own (Levinson, 1997). The problems of limited classroom and lack of other infrastructure in imparting training and education on a massive scale is overcome by the e-Learning mode, but, it also gives rise to a "copy-paste" tendency on part of the students, for example. It is therefore necessary to develop standards and guidelines to establish the credibility of the e-Learning courses to gain wider acceptance by the employers. Of course other problems like non-availability of reliable electricity supply, high prices of computer and low network connectivity and bandwidth are to be addressed by the authorities to make the best use of the ICTs by individuals and institutions located in any part of the country.

In our view, e-learning, which encompasses literacy, technical skill and intellectual capital formation support by the modern library services, would give an opportunity to a large Indian populace to join the mainstream of development and contribute to build a civic society. Due to their several advantageous features, the ICTs, if implemented with professional care, would certainly facilitate in bringing about such a transformation. To that end adequate investments in ICTs and concerted efforts for promoting their applications in learning environments should get the highest priority.

\section{References}

Alexander, Bryan, (2006). Web 2.0: a new wave of innovation for teaching and learning? Educause Review, 41(2), available online at 〈http://www.educause.edu/apps/er/erm06/ erm0621.asp?bhcp $=1\rangle$.

Atkins, Daniel E., et al. (2003). Revolutionizing science and engineering through cyberinfrastructure. Report of the National Science Foundation Blue Ribbon Advisory Panel on
Cyberinfrastructure, available online at 〈http://www. communitytechnology.org/nsf_ci_report $>$.

Balakrishnan, N. (2005). Universal digital library-Future directions. Journal of Zhejiang University, 6(11), 1204-1205 available online at 〈http://www.zju.edu.cn/jzus $\rangle$.

CARL e-Learning Working Group, (2005). Final report on Libraries and e-Learning, available online at 〈http://www. carl-abrc.ca/projects/e_learning/pdf/final-report.pdf $\rangle$.

Chandra, Smita. (2002). Information in a networked world: The Indian perspective. International Information and Library Review, 34, 235-246.

Dempsey, Lorcan, (2006). The (Digital) library environment : ten years after. Ariadne, 46, available online at 〈http:// www.ariadne.ac.uk/issue46/dempsey/ $>$.

Detecon and Diebold Consultants, (2002). Opinion paper. E-Learning in developing countries, available online at 〈http://www1. worldbank.org/education/stuttgart_conference/download/6_2. pdf $>$.

Downes, Stephens, E-learning 2.0, eLearn Magazine, available online at $\langle$ http://www.elearnmag.org/subpage.cfm?section= articles\&article $=29-1\rangle$.

ELAG 2005 WS, (2005). Fig. 2: E-learning and libraries. Presented at Geneve, June 2005. available online at 〈http: / /elag2005. web.cern.ch/elag2005/media/WS5report.ppt $\rangle$.

Ghosh, Gautam, E-Learning: rhetoric vs. reality, available online at $\langle$ http://www.humanlinks.com/manres/articles/e_learning. htm $\rangle$.

Good, Robin, (2006). Electronic portfolios: what are they?, available online at 〈http://www.masternewmedia.org/news/ 2006/03/10/electronic_portfolios_what_are_they.htm\# $\rangle$.

Information for All Programme (IFAP). Online at <http:// portal.unesco.org/ci/en.php-URL_ID=167\&URL_DO=DO_topic \&URL_section=201.html $>$.

Jain, S.P., \& Goria, Sunil, (2006). Digital Library for Indian Farmers (DLIF) using open source software: a strategic plan. Presented at 72nd IFLA General Conference and Council, Seoul, Korea, 20-24 August 2006, available online at 〈http://www.ifla.org/IV/ifla72/papers/103-Jain_Goria-en. pdf $\rangle$.

Kanjilal, Uma, \& Ghosh, S.B. Developing e-Learning prototype for library management - a case study. Available online at $\langle$ http://www.unige.ch/biblio/ses/IFLA/sat1-Ghosh.pdf $\rangle$.

Karisiddappa, C.R. (2004). Library and information science curriculum for the developing countries. World Library and Information Congress: 70th IFLA General Conference and Council, 22-27 August 2004, Buenos Aires, Argentina, available online at 〈http://www.ifla.org/IV/ifla70/papers/ 062e-Karisiddappa.pdf $\rangle$.

Kaul, H. K. (2006). Developing libraries as knowledge centres: the strategies for knowledge management. In H. K. Kaul, \& G. Sen (Eds.), Library and Information Networking-NACLIN 2005 (pp. 72-87). New Delhi: DELNET_Developing Library Network.

Levinson, P. (1997). Learning Unbound: Online Education and the Mind's Academy. Analog, 48-57.

Mannes, Jack. M. (2006). Library 2.0 theory: web 2.0 and its implications for libraries. Webology, 3(2) available online at 〈http://www.webology.ir/2006/v3n2/a25.html〉.

Messerchmitte, D. G. (2003). Opportunities for research libraries in the NSF cyberinfrastructure program. ARL Bimonthly Report, 229 available online at <http://www.arl.org/newltr/ 229/cyber.html >.

Mohan, R.N., \& Ramkrishnan, S. (2006). GARUDA: India's national grid computing initiative. CTWatch Quarterly, available online at 〈http://www.ctwatch.org/quarterly/articles/2006/ 02 /garuda-indias-national-grid-computing-initiative/ $>$. 
Mukhopadhyay, Parthasarathi, (2006). VidyaOnline: Design and development of a FOSS based Virtual Learning Environment on Library and Information Science at Vidyasagar University, West Bengal. Presented at DRTC-ICT conference on ICT for facilitating digital learning environment, 11-13 January 2006, DRTC, Bangalore, available online at <https://drtc. isibang.ac.in/handle/1849/208>.

OCLC e-Learning Taskforce, (2003). Libraries and the enhancement of e-learning. Available online at 〈http://www5. oclc.org/downloads/community/elearning.pdf $\rangle$.

Patel, Dimple, (2006). E-Learning and its impact on LIS profession, Presented at DRTC-ICT conference on ICT for facilitating digital learning environments, 11-13 January 2006, DRTC, Bangalore, available online at 〈https://drtc. isibang.ac.in/handle/1849/231 >.

Patkar, Vivek (2006). Library profession in evolving information environment. Service for Communicators, 25(7), 5-7.

Patkar, Vivek, \& Chandra, Smita. (2006). E-Research and the ubiquitous open grid digital libraries of the future.
Presented at the 72nd IFLA general conference and council, Seoul, 20-24 August 2006, available online at 〈http://www.ifla.org/IV/ifla72/papers/140-Patkar_Chandraen.pdf $\rangle$.

Singh, Kanwar Pal. (2002). Multimedia and elearning: a new direction for productivity promotion and enhancement. Report of the APO seminar on multimedia for productivity promotion and enhancement (With Special Focus on e-Learning), Republic of China, 25-29 March 2002.

SPACE India, October 2005-March 2006, pp.15-16.

Tosh, David, \& Werdmuller, Ben. Fig. 1: Creation of a learning landscape: weblogging and social networking in the context of e-portfolios. From a presented of the Elgg Development Team, Powerpoint at <http://elgg.net/dtosh/files/260/568/ creation_of_a_learning_landscape.ppt $\rangle$.

Yajnik, Nilay M. E-Learning technologies for rural India, available online at 〈http://www.cdac.in/HTmL/pdf/ Session2.3.pdf $>$.

Available online at www.sciencedirect.com

\section{$\because$ ScienceDirect}

